\title{
Carborane guests for cucurbit[7]uril facilitate strong binding and on demand removal
}

\author{
Anna Kataki-Anastasakou ${ }^{1}$, Jonathan C. Axtell ${ }^{1,2}$, Selena Hernandez ${ }^{1}$, Rafal M. Dziedzic ${ }^{1}$, Gary J. \\ Balaich $^{3}$, Arnold L. Rheingold ${ }^{4}$, Alexander M. Spokoyny ${ }^{1}$, Ellen M. Sletten ${ }^{1, *}$ \\ ${ }^{1}$ Department of Chemistry and Biochemistry, University of California Los Angeles, 607 Charles E. Young Drive East, Los An- \\ geles, California 90095, USA. \\ 2 Present address: Core R\&D, Chemical Science, Dow Inc., Midland, MI, 48674. \\ ${ }^{3}$ Department of Chemistry United States Air Force Academy, 2355 Fairchild Drive, Suite 2N-255, Colorado, 80840, USA. \\ ${ }^{4}$ Department of Chemistry and Biochemistry, University of California, San Diego, 9500 Gilman Drive, La Jolla, California \\ 92093, USA.
}

\begin{abstract}
High affinity guests have been reported for the macrocyclic host cucurbit[7]uril (CB[7]), enabling widespread applications, but preventing $\mathrm{CB}$ [7] materials from being returned to their guest-free state for reuse. Here we present polyhedral boron clusters (carboranes) as strongly-binding, yet easily removable, guests for $\mathrm{CB}$ [7]. Aided by a Pd-catalyzed coupling of an azide anion, we prepared boron-functionalized 9-amino and 9-ammonium modified ortho-carboranes that bind to $\mathrm{CB}[7]$ with a $K_{a}=10^{10} \mathrm{M}^{-1}$. Upon treatment with base, the orthocarboranes readily undergo deboronation to yield anionic nido-carborane, a poor guest of $\mathrm{CB}[7]$, facilitating recovery of guest-free $\mathrm{CB}[7]$. We showcase the utility of the modified ortho-carborane guest by recycling a $\mathrm{CB}[7]-$ functionalized resin. With this report, we introduce stimuli-responsive decomplexation as an additional consideration in the design of high affinity host-guest complexes.
\end{abstract}

Molecular recognition is ubiquitous within the natural world with the genetic code, enzymes, and immune systems all reliant on non-covalent interactions between biomolecules. ${ }^{1,2}$ These phenomena have inspired chemists to develop host-guest complexes in hopes of achieving comparable degrees of specificity for applications in functional materials, ${ }^{3}$ sensors, ${ }^{4}$ biological assays, ${ }^{5}$ and therapeutics. ${ }^{6-9}$ Much of the early molecular recognition work involved crown ether, cyclophane, and cyclodextrin hosts that exhibit modest binding affinities $\left(K_{a} \leq 10^{5} \mathrm{M}^{-}\right.$ $\left.{ }^{1}\right) .{ }^{10}$ More recently, there has been a focus on the development of high affinity $\left(K_{a} \geq 10^{10} \mathrm{M}^{-1}\right)$ host-guest complexes that rival the binding affinities of Nature's best molecular recognition systems: antibody-antigens and (strept)avidin-biotin. ${ }^{11}$ High binding affinity complexes facilitate the expansion of host-guest chemistry to applications in dilute, complex settings and decrease the need to exploit multivalency. ${ }^{12}$ However, large $K_{\mathrm{a}}$ values also lead to difficulties in dissociating the pair on-demand, limiting the reversibility, and therefore the flexibility of the system (Figure 1A)..$^{13}$ Here we present "decomplexation", the ability to remove a guest on demand, as an important feature in the design of high affinity host-guest pairs. (Figure 1B).

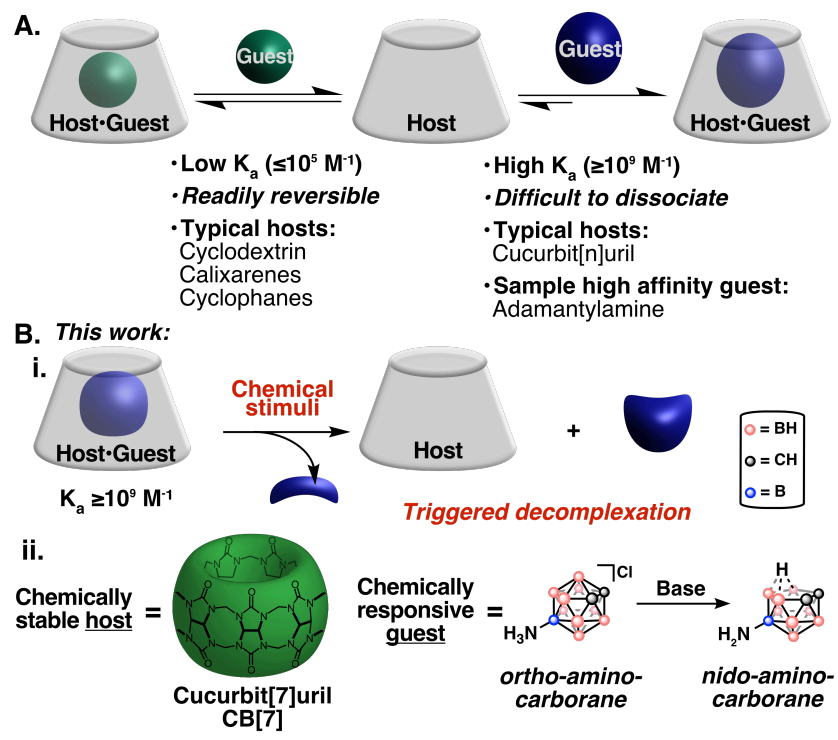

Figure 1. (A) Synthetic host-guest pairs are typically characterized either by low binding affinities and reversible association or high binding affinities with limited dissociation. (B) (i) This work presents triggered decomplexation as an advantageous property for high-affinity host-guest complexes. (ii) We demonstrate this concept with a cucurbit[7]uril (CB[7]) and 9-amino-ortho-carborane host-guest pair that undergoes decomplexation via a mild chemical trigger. 
Cucurbiturils, cyclic oligomers of glycoluril linked by methylene units, have become the host of choice for high-affinity complexes. ${ }^{14,15}$ The heptamer, cucurbit[7]uril (CB[7]), displays the largest binding affinities, with the highest reported $K_{a}$ being $10^{15} \mathrm{M}^{-1}$ for complexation with 1,6- $\mathrm{N}$-trimethylammonium diamantine at $\mathrm{pH}$ 4.75. ${ }^{16}$ The high binding affinity was achieved obtaining complete displacement of the encapsulated water molecules and optimizing the alignment of cationic functionality with the carbonyl rings. ${ }^{17}$ Other high affinity guests for $\mathrm{CB}[7]$ are adamantylamine $\left(K_{a}=10^{12} \mathrm{M}^{-1}\right)$ and derivatives $\left(K_{a}=10^{4-15} \mathrm{M}^{-1}\right)^{16,18}$ as well as functionalized ferrocenes $\left(K_{a}=10^{9-15} \mathrm{M}^{-1}\right){ }^{15}$

Due to the high binding affinities presented by various cationic guests, the $\mathrm{CB}[7]$ scaffold has been extensively studied as a biotin-(strept)avidin mimic. ${ }^{19-23} \mathrm{CB}[7]$ has also found use in small molecule separation, ${ }^{24}$ dynamically crosslinked polymers, ${ }^{3,25}$ surface patterning ${ }^{26,27}$ and sensor development. ${ }^{28}$ In many of these applications, $\mathrm{CB}[7]$ is immobilized on solid-supports and the high binding affinity of guests with $\mathrm{CB}[7]$ render these materials one-time use. If compounds captured by the immobilized $\mathrm{CB}[7]$ need to be released, a higher affinity guest is introduced to displace the captured material. The difficulty in returning surfaces and devices containing $\mathrm{CB}[7]$ to their initial guest-free state limits the use of $\mathrm{CB}[7]$ to highly specialized applications where cost and scale are not significant factors.

To enable recycling of $\mathrm{CB}$ [7]-containing materials, we designed a high affinity guest for $\mathrm{CB}$ [7] that upon chemical treatment could be transformed into a weak guest for easy removal. A guest that can undergo decomplexation could either be employed as the primary guest in the experiment or could be used in a separate step to displace an application-specific guest and then undergo decomplexation to allow the $\mathrm{CB}$ [7] material to return to its original guest-free state. To date, methods for high-affinity guest removal from the $\mathrm{CB}$ [7] cavity are limited to excessive salt treatment that suffer the same limitations as biotin-(strept)avidin systems. ${ }^{23,29}$

In our search for ideal guests to fit the criteria of both high binding affinity to $\mathrm{CB}[7]$ and the ability to be removed by triggered decomplexation, we looked to guests with shape complementarity to the cavity of $\mathrm{CB}[7]$ that could be readily transformed into a fragment that is poorly encapsulated by $\mathrm{CB}[7] .^{18,30-32}$ Icosahedral carboranes of the type $\mathrm{C}_{2} \mathrm{~B}_{10} \mathrm{H}_{12}$ appeared primed to meet these requirements. These 3D aromatic clusters ${ }^{33-35}$ bear a close topological similarity to adamantane $e^{36,37}$ and one of the three isomers, ortho-carborane, has previously been employed as a guest for $\mathrm{CB}$ [7], although no $K_{\mathrm{a}}$ was reported. ${ }^{38}$ Importantly, carboranes can undergo Lewis base-mediated boron vertex removal (termed "deboronation") to generate the nido-7,8- $\mathrm{C}_{2} \mathrm{~B}_{9} \mathrm{H}_{11}$ anion
(Figure 1B). ${ }^{39-41}$ Ortho- and meta-carborane have significantly different rates of deboronation, as well as distinct dipole moments. ${ }^{36,42}$ We set out to explore the binding affinities of derivatives of these two carborane isomers with $\mathrm{CB}[7]$ and their potential for removal upon deboronation to create a reliable recycling system for the $\mathrm{CB}[7]$. We hypothesized that ortho-carboranes would be readily decomplexed from $\mathrm{CB}[7]$ upon base treatment, while the meta-carborane would act as a control.

The electronic non-uniformity of carboranes is widely recognized, resulting in different electronic influences on bound substituents depending on the cage vertex..$^{43}$ The B9 positions of ortho- and meta-carborane are the most electron-rich positions in the corresponding carboranes. Given the similar inductive electronic effects of B-bound substituents on carboranes compared to bulky alkyl groups, we targeted $\mathrm{N}$-substitution at the $\mathrm{B}(9)$ vertices of the carboranes to most closely mimic the electronic environment of adamantylamine. Despite a variety of methods to functionalize ortho- and meta-carborane, ${ }^{44-}$ 48 the synthetic methodology developed for the amination of 9-Br-meta-carborane ${ }^{49}$ is incompatible with 9-Brortho-carborane (1) due to deboronation by the basic reaction conditions. Alternative routes to nitrogen-substituted ortho-carboranes were similarly unsuccessful for the generation of free amine at the B9-position. ${ }^{50}$

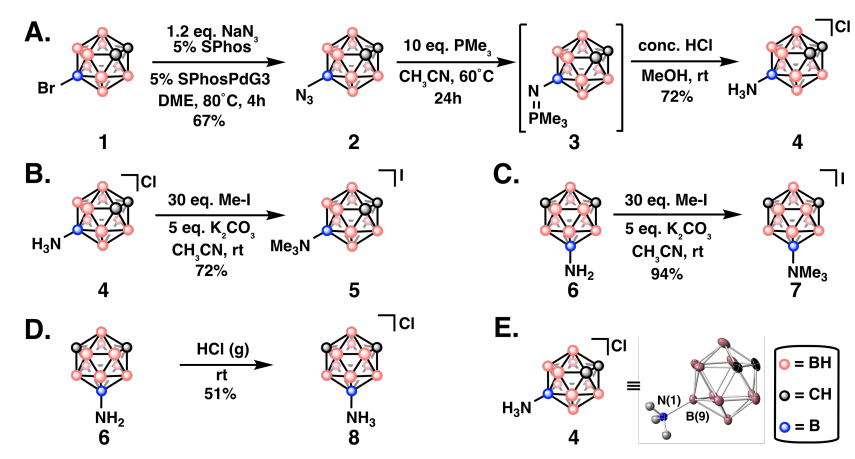

Figure 2. (A) Synthetic route to 9-amino-ortho-carborane (4) through 9-azido-ortho-carborane (2). (B, C) Treatment of 4 and 6 with $\mathrm{Me}-\mathrm{I}$ affords trimethylated derivatives 5,7. (D) Formation of salt 8. (E) Single crystal X-ray diffraction of $\mathbf{4}$ (chloride counterion and cage-based hydrogens removed for clarity). SPhos and SPhosPdG3 are the Pd(II) catalysts and precatalysts used for the transformation, respectively.

Thus, a new synthetic route (Figure $2 \mathrm{~A}$ ) to furnish the B9 aminated ortho-carborane target was necessary. Treatment of 9-Br-ortho-carborane (1) with $\mathrm{NaN}_{3}$ under Pdcatalyzed cross-coupling conditions afforded the desired 9- $\mathrm{N}_{3}$-ortho-carborane $(\mathbf{2})^{49}$ in $67 \%$ yield. ${ }^{51}$ This is a rare example of Pd-catalyzed cross-coupling of an azide anion. Subsequent Staudinger reduction using trimethylphosphine $\left(\mathrm{PMe}_{3}\right)$ and hydrolysis with concentrated $\mathrm{HCl}$ gave the desired hydrochloride salt 4 , confirmed by crystallography (Figure $2 \mathrm{E}$ ), in $72 \%$ overall yield. To probe 
the effect of a permanent positive charge on the guest, the trimethylammonium derivatives of $\mathbf{4}$ and $\mathbf{6}$ ( 5 and $\mathbf{7}$, respectively) were prepared in good yield through treatment with Mel (Figure 2B,C). We prepared the analogous hydrochloride salt 9- $\mathrm{NH}_{3}$-meta-carborane (8) by treating the corresponding amine with gaseous $\mathrm{HCl}$ (Figure 2D) to aid in binding affinity investigations.
A.
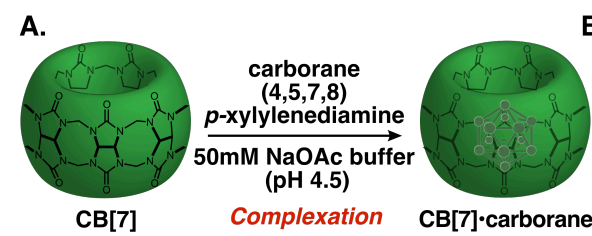

B.

\begin{tabular}{|c|c|}
\hline$\#$ & $\mathbf{K}_{\mathrm{a}}\left(\mathrm{M}^{-1}\right)$ \\
\hline $\mathbf{4}$ & $(3 \pm 2) \times 10^{10}$ \\
\hline $\mathbf{5}$ & $(1.1 \pm 0.2) \times 10^{10}$ \\
\hline $\mathbf{8}$ & $(2 \pm 2) \times 10^{10}$ \\
\hline $\mathbf{7}$ & $(1.8 \pm 0.8) \times 10^{9}$ \\
\hline
\end{tabular}

Figure 3. (A) Association of carborane with $\mathrm{CB}[7]$. (B) Binding affinities of water-soluble carborane derivatives $(\mathbf{4}, \mathbf{5}, \mathbf{7}, \mathbf{8})$ (1 eq.) determined by ${ }^{1} \mathrm{H}$ NMR spectroscopy competition experiments with $p$-xylylenediamine ( 2 eq.) in $50 \mathrm{mM} \mathrm{NaOAc}$ buffer. ${ }^{18}$

The aqueous solubility of the amino and ammonium functionalized carboranes $(4,5,7,8)$ allowed binding affinities to be determined by ${ }^{1} \mathrm{H}-\mathrm{NMR}$ spectroscopy in acetate buffer. Competition experiments against $p$-xyIylenediamine were performed. ${ }^{18}$ Interestingly, three of the four 9-aminocarboranes $(4,5,8)$ displayed similar binding affinities of $K_{a} \approx 10^{10} \mathrm{M}^{-1}$ in $\mathrm{pH} 4.5 \mathrm{NaOAc}$ buffer (Figure 3). The exception was 9-trimethylammoniummeta-carborane (7) where methylation decreases the $K_{\mathrm{a}}$ by an order of magnitude. We note that the binding affinities are not quite as high as those observed with adamantylamine, despite the structural analogy between carborane and adamantane. ${ }^{52}$ This could be could be due to the greater inherent net dipole of carboranes that alters the positioning in the $\mathrm{CB}[7]$ hydrophobic pocket. Nevertheless, at $K_{a}=10^{10} \mathrm{M}^{-1}$ we have established carboranes as a new class of high affinity guests for $\mathrm{CB}[7]$.

Next, we investigated the ability for carborane guests to be decomplexed from $\mathrm{CB}[7]$ on demand. For initial studies we employed ortho-and meta-carborane, which we predicted to have orthogonal decomplexation properties (Figure 4A). We characterized the CB[7] •carborane complexes in trifluoroacetic acid (TFA), due to limited water solubility of unfunctionalized carborane. ${ }^{62}$ We found that a stable complex between $\mathrm{CB}[7]$ and ortho- and metacarborane (35-55 mM, 1.2 eq) readily formed upon sonication and could be purified by washing with organic solvent. Carborane is clearly seen in the aqueous solution of host-guest complex via ${ }^{11} \mathrm{~B}-\mathrm{NMR}$ spectroscopy when both ortho- (9) and meta-carborane (10) are introduced (Figure S7).
A.

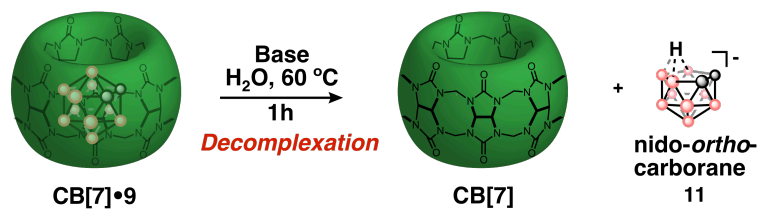

B.

\begin{tabular}{|c|c|c|c|c|c|c|}
\hline Entry & Carborane & Base & 1h & 2h & $\mathbf{8 h}$ & $\mathbf{2 4 h}$ \\
\hline 1 & $\mathbf{9}$ & $\mathrm{HNMe}_{2}(1 \mathrm{M}$ THF $)$ & $9 \%$ & $17 \%$ & $45 \%$ & $86 \%$ \\
\hline 2 & $\mathbf{9}$ & $\mathrm{HNMe}_{2}\left(40 \%\right.$ in $\left.\mathrm{H}_{2} \mathrm{O}\right)$ & $<5 \%$ & $<5 \%$ & $<5 \%$ & $<5 \%$ \\
\hline 3 & $\mathbf{9}$ & Pyridine & $<5 \%$ & $<5 \%$ & $<5 \%$ & $<5 \%$ \\
\hline 4 & $\mathbf{9}$ & Piperidine & $>95 \%$ & $>95 \%$ & $>95 \%$ & $>95 \%$ \\
\hline 5 & $\mathbf{4}$ & Piperidine & $8 \%$ & $19 \%$ & $>95 \%$ & $>95 \%$ \\
\hline 6 & $\mathbf{1 0}$ & Piperidine & $<5 \%$ & $<5 \%$ & $<5 \%$ & $<5 \%$ \\
\hline 7 & $\mathbf{8}$ & Piperidine & $<5 \%$ & $<5 \%$ & $<5 \%$ & $<5 \%$ \\
\hline
\end{tabular}

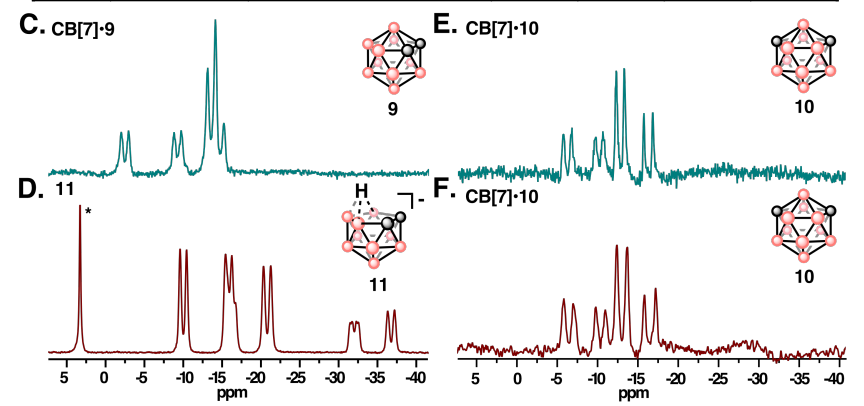

Figure 4: (A) Decomplexation of the $\mathrm{CB}[7] \bullet 9$ complex through deboronation of ortho-carborane (9) with base to yield to nido-ortho-carborane (11) and free CB[7]. (B) Table of conditions screened to evaluated the decomplexation of CB[7] •carborane complexes. Generation of $\mathbf{1 1}$ was calculated by relative integration of baseline corrected ${ }^{11} B$ NMR spectra. $\mathrm{CB}[7]$.carborane complex and base (5 equiv.) were combined in $\mathrm{H}_{2} \mathrm{O}$, stirred at $60{ }^{\circ} \mathrm{C}$, and monitored by ${ }^{11} \mathrm{~B}$ NMR spectroscopy. (E, F) ${ }^{11} \mathrm{~B}$ NMR spectra taken before (C) and after (D) 1 h of subjecting $\mathrm{CB}[7] \bullet 9$ complex $(\mathrm{B}, \mathrm{C})$ or $\mathrm{CB}[7] \bullet 10$ complex $(\mathrm{E}, \mathrm{F})$ to $20 \%$ piperidine $/ \mathrm{H}_{2} \mathrm{O}(\mathrm{V} / \mathrm{v})$ at $60^{\circ} \mathrm{C}$. * denotes borate side-product known to form during 9 deboronation.

We screened a panel of bases that are known to deboronate ortho-carborane in solution to efficiently yield nido-ortho-carborane (Figure 4B). For decomplexation of ortho-carborane from $\mathrm{CB}$ [7], we found that aqueous solubility was the most important factor determining the rate of deboronation as exemplified by piperidine's superiority compared to dimethylamine ( $\mathrm{HNMe}_{2}$ ) (Figure 3B, entries $1-2,9)$. The volatility of dissolved $\mathrm{HNMe}_{2}$ likely also contributes to its inferior deboronating ability under the reaction conditions (Figure 4B, entries 1-2).

After establishing $50 \%$ aqueous piperidine at $60^{\circ} \mathrm{C}$ as optimal decomplexation conditions for $\mathbf{C B}[7] \bullet 9$, we applied similar conditions to the meta-carborane complex (CB[7]•10). Distinct differences are immediately apparent with the ortho-carborane undergoing deboronation to yield nido-ortho-carborane, 11, while no transformation was apparent with the meta-carborane (Figure $4 C-F$, Figure $4 B$, entry 6 ). These results are consistent with the diminished electrophilicity of the boron vertices 
adjacent to carbon vertices in $\mathbf{1 0}$ as compared to $\mathbf{9}$ and demonstrate the potential for orthogonal chemical behavior of sterically identical guest molecules encapsulated by $\mathrm{CB}[7]$. Importantly, the 9-aminocarboranes 4 and $\mathbf{8}$ (Figure $4 \mathrm{~B}$, entries 5,7 ) follow the same deboronation trends as the unfunctionalized compounds.

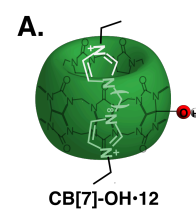

B.

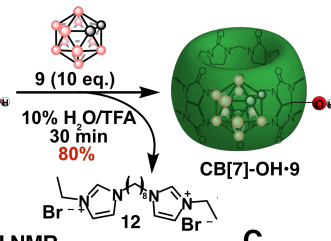

(i) $50 \%$ aq. $1 \mathrm{~h}$ (ii) DCM Wash
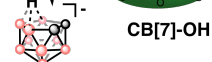

11

[7]-OH
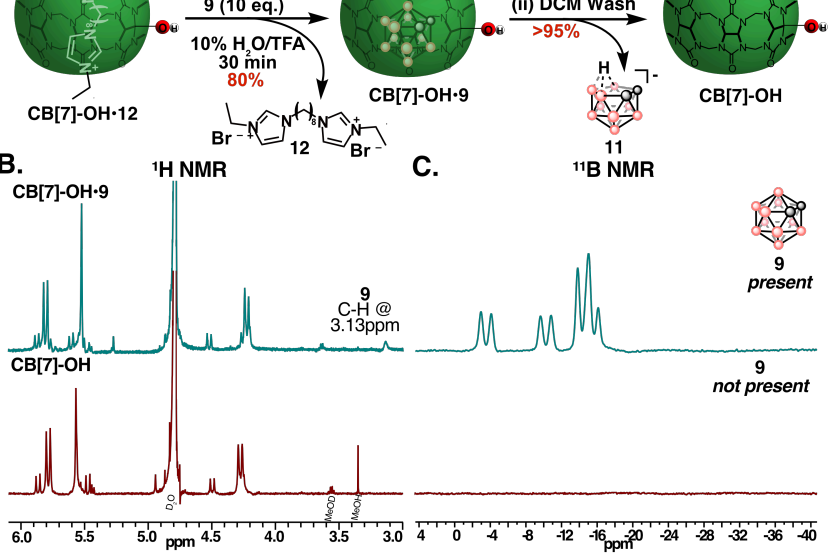

Figure 5: (A) Straightforward isolation of guest-free CB[7]-

$\mathrm{OH}$ by guest exchange with 9 and subsequent decomplexation with piperidine. (B,C) Displacement of $\mathbf{1 2}$ by ortho-carborane (9) and formation of $\mathrm{CB}$ [7]-OH॰9 (top, blue) and decomplexation and removal of (11) to form a guest-free CB[7]-OH cavity (bottom, red) was observed by ${ }^{1} \mathrm{H}-\mathrm{NMR}(\mathrm{B})$ and ${ }^{11}$ B-NMR spectroscopy (C).

To showcase the utility of the "on-demand" decomplexation offered by the ortho-carborane guests we used 9 to isolate $\mathbf{C B}[7]-\mathrm{OH}$ (Figure $5 \mathrm{~A}$ ). $\mathbf{C B}[7]-\mathrm{OH}$ is an important intermediate for the creation of $\mathrm{CB}$ [7] conjugates, materials, and devices. $\mathrm{CB}$ [7] can be readily monohydroxylated by treatment of $\mathrm{CB}[7] \bullet 12$ with persulfate salts; however we found efficient removal of $\mathbf{1 2}$ from the $\mathrm{CB}[7]-\mathrm{OH}$ cavity to be difficult. ${ }^{29}$ Gratifyingly, 12 could be displaced with 9 in as little as 30 min in a $\mathrm{H}_{2} \mathrm{O}$ /TFA mixture. Upon evaporation of the TFA, treatment with piperidine for 1 hour followed by a dichloromethane wash provided guest free $\mathbf{C B}[7]-\mathrm{OH}$. The progress of complexation of $\mathbf{9}$, deboronation, and removal of $\mathbf{1 1}$ by washing can be easily monitored by ${ }^{1} \mathrm{H}$ NMR and ${ }^{11} \mathrm{~B}$ NMR spectroscopy (Figure $5 B, C$ ). In our hands, this is the fastest and highest yielding procedure to synthesize and isolate guest-free CB[7]-OH to-date. The decomplexation method was also used to prepare guest-free $\mathbf{C B}[\mathbf{7}]-\mathbf{N}_{\mathbf{3}}$, another important functionalized $\mathbf{C B}[7]{ }^{53,54}$

To demonstrate the ability to recycle $\mathrm{CB}$ [7]-constructs via decomplexation of ortho-carborane guests, we conjugated $\mathbf{C B}[7]-\mathbf{N}_{3}{ }^{53,55}$ to bicyclononyne-functionalized Wang resin (Wang-BCN, Figure 6A, Scheme S2) using copper-free click chemistry and confirmed successful immobilization using fluorescein adamantylamine conjugate 13.

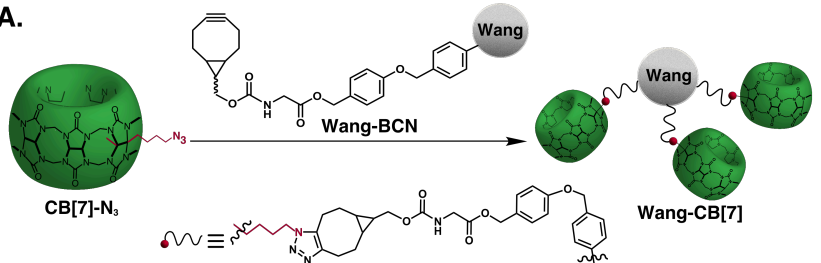

B.
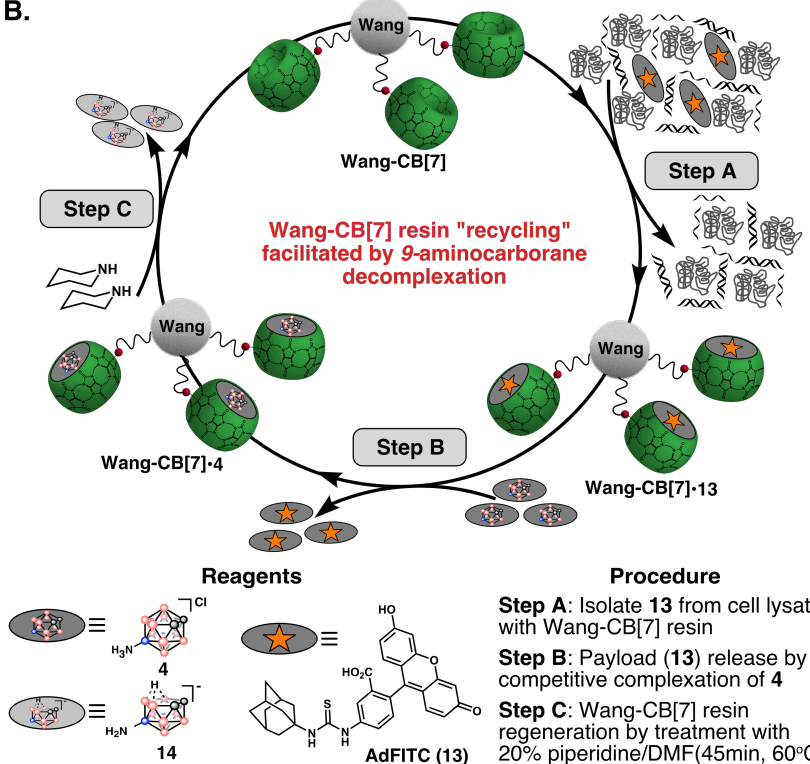

eagents

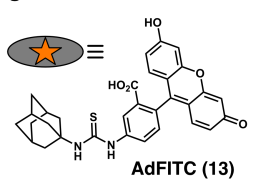

Step A: Isolate 13 from cell lysate with Wang-CB[7] resin

Step B: Payload (13) release by competitive complexation of 4 Step C: Wang-CB[7] resin regeneration by treatment with C. Round 1

Round 2

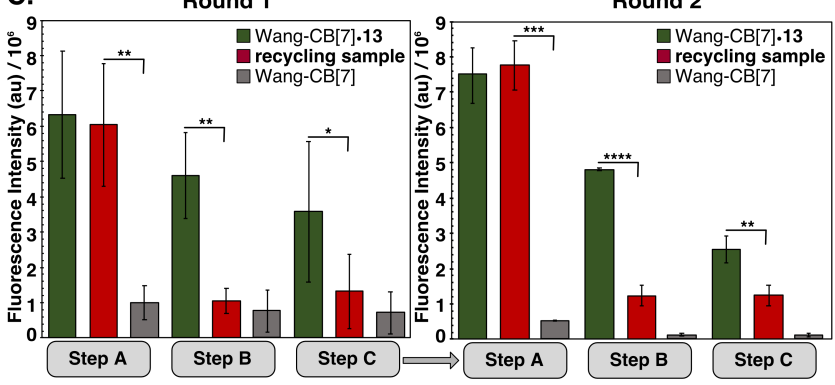

Figure 6: (A) Scheme depicting attachment of $C B[7]-\mathrm{N}_{3}$ to bicyclononyne (BCN)-functionalized Wang resin to produce Wang-CB[7]. (B) Wang-CB[7] was used to isolate payload, 13, from Jurkat lysate in $50 \% \mathrm{DMF} / \mathrm{H}_{2} \mathrm{O}$ (Step $\mathrm{A}$ ), and was regenerated by complexation of $\mathbf{4}$ (Step B) followed by decomplexation (Step C). (C) Fluorescence of Wang-CB[7] throughout the recycling sequence (red) compared to fluorescent Wang-CB[7]•13-samples not incubated with $\mathbf{4}$ in Step B-(green) and non-fluorescent Wang-CB[7]-samples not incubated with $\mathbf{1 3}$ or $\mathbf{4}$ in Steps A and B-(gray). Error bars represent standard deviation of 3 replicate samples. ${ }^{*} \mathrm{P} \leq 0.05,{ }^{* *} \mathrm{P} \leq 0.01,{ }^{* * *} \mathrm{P} \leq 0.001,{ }^{* * * * P} \mathrm{P} \leq 0.0001$.

The resulting Wang-CB[7] resin was added to Jurkat lysate $(2 \mathrm{mg} / \mathrm{mL})$ containing 13 to selectively isolate the fluorescent guest from a complex mixture (Figure 6B, Step A). After washing away cell lysate, displacement with 4 rapidly releases $\mathbf{1 3}$ (Figure 6B, Step B). Finally, treatment with piperidine deboronates 4 to produce 14 and regenerate Wang-CB[7] (Figure 6B, Step C). The success of each step was monitored through the fluorescence of Wang-CB[7] (red) and compared to fluorescent 
Wang-CB[7]•13, where displacement by 4 was omitted (green) and non-fluorescent Wang-CB[7], where addition of $\mathbf{1 3}$ and $\mathbf{4}$ were omitted (gray) controls (Figure 6C). The cycle was repeated twice, at which point signal became too low due to significant loss of resin in the washing steps. Recycling of the resin represents a novel method of reusing precious $\mathrm{CB}$ [7]-constructs that can be applied for payload isolation in many biological and materials application settings.

In this report, we present a new cucurbit[7]uril guest scaffold based on icosahedral boron clusters (carboranes), which are high affinity $\left(\mathrm{K}_{\mathrm{a}} \approx 10^{10} \mathrm{M}^{-1}\right)$ binders for $\mathrm{CB}[7]$ that can be removed on demand through deboronation chemistry. We designed 9-aminocarborane guests to mimic the size and charge of adamantylamine and took advantage of the differential reactivity of carborane isomers to prepare guests that were (ortho) and were not (meta) readily deboronated. To access 9-aminoortho-carborane, we report a rare example of Pd-catalyzed cross coupling with azide. We utilized this scaffold to efficiently prepare guest-free $\mathrm{CB}[7]-\mathrm{OH}$ and showcase the opportunity to "recycle" $\mathrm{CB}$ [7]-constructs that can be continuously employed in biological assays and materials applications. We envision this work will overcome limitations of traditional biotin-(strept)avidin systems and enable $\mathrm{CB}[7]$ sensors and technologies. This work further highlights how unique stimuli-responsive features of boron clusters can aid the development of new complex hybrid chemical systems. ${ }^{56-64}$

\section{AUTHOR INFORMATION}

\section{Corresponding Author}

*Email: Sletten@chem.ucla.edu (E.M.S.)

\section{Funding Sources}

This work was supported by NIGMS grants to E.M.S. (1DP2GM13268) and A.M.S. (R35GM124746). R.M.D. is a National Defense Science and Engineering Graduate Fellow and S.H. is an Undergraduate Research Scholars Program awardee.

\section{ACKNOWLEDGMENT}

We thank Margeaux Miller for her contribution in devising the recycling experiment and Rachael Day, Emily Cosco, and Daniel Estabrook for their critical reading of the manuscript.

\section{REFERENCES}

(1) Lodish, H.; Berk, A.; Zipursky, S. L.; Matsudaira, P.; Baltimore, D.; Darnell, J. Molecular Cell Biology 4th Edition; W. H. Freeman, 2000.

(2) Frieden, E. Non-Covalent Interactions: Key to Biological Flexibility and Specificity. J. Chem. Educ. 1975, 52, 754-761.

(3) Appel, E. A.; del Barrio, J.; Loh, X. J.; Scherman, O. A. Supramolecular Polymeric Hydrogels. Chem. Soc. Rev. 2012, 41, 6195-6214.

(4) Mako, T. L.; Racicot, J. M.; Levine, M. Supramolecular Luminescent Sensors. Chem. Rev. 2019, 119, 322-477.

(5) Agasti, S. S.; Liong, M.; Tassa, C.; Chung, H. J.; Shaw, S. Y.; Lee, H.; Weissleder, R. Supramolecular Host-Guest Interaction for Labeling and Detection of Cellular Biomarkers. Angew. Chemie Int. Ed. 2012, $51,450-454$.

(6) Cui, H.; Xu, B. Supramolecular Medicine. Chem. Soc. Rev. 2017, 46, 6430-6432.

(7) Webber, M. J.; Appel, E. A.; Vinciguerra, B.; Cortinas, A. B.; Thapa, L. S.; Jhunjhunwala, S.; Isaacs, L.; Langer, R.; Anderson, D. G. Supramolecular PEGylation of Biopharmaceuticals. Proc. Natl. Acad. Sci. U. S. A. 2016, 113, 14189-14194.

(8) Webber, M. J.; Langer, R. Drug Delivery by Supramolecular Design. Chem. Soc. Rev. 2017, 46, 6600-6620.

(9) Wang, L.; Li, L.; Fan, Y.; Wang, H. Host-Guest Supramolecular Nanosystems for Cancer Diagnostics and Therapeutics. Adv. Mater. 2013, 25, 3888-3898.

(10) Oshovsky, G. V; Reinhoudt, D. N.; Verboom, W. Supramolecular Chemistry in Water. Angew. Chem. Int. Ed 2007, 46, 2366-2393.

(11) Houk, K. N.; Leach, A. G.; Kim, S. P.; Zhang, X. Binding Affinities of Host-Guest, Protein-Ligand, and Protein-Transition-State Complexes. Angew. Chemie Int. Ed. 2003, 42, 4872-4897.

(12) Fasting, C.; Schalley, C. A.; Weber, M.; Seitz, O.; Hecht, S.; Koksch, B.; Dernedde, J.; Graf, C.; Knapp, E.-W.; Haag, R. Multivalency as a Chemical Organization and Action Principle. Angew. Chemie Int. Ed. 2012, 51, 10472-10498.

(13) Liu, W.; Samanta, S. K.; Smith, B. D.; Isaacs, L.; Norquest, K. A.; Smith, B. D.; Smith, B. D.; Pei, Z.; Hooley, R. J.; Selvapalam, N.; Ryu, S.; Kim, K.; Gilson, M. K.; Kim, K.; Inoue, Y. Synthetic Mimics of Biotin/(Strept)Avidin. Chem. Soc. Rev. 2017, 46, 2391-2403.

(14) Masson, E.; Ling, X.; Joseph, R.; Kyeremeh-Mensah, L.; Lu, X. Cucurbituril Chemistry: A Tale of Supramolecular Success. RSC Adv. 2012, 2, 1213-1247.

(15) Shetty, D.; Khedkar, J. K.; Park, K. M.; Kim, K. Can We Beat the BiotinAvidin Pair?: Cucurbit[7]Uril-Based Ultrahigh Affinity Host-Guest Complexes and Their Applications. Chem. Soc. Rev. 2015, 44, 87478761.

(16) Cao, L.; Šekutor, M.; Zavalij, P. Y.; Mlinarić-Majerski, K.; Glaser, R.; Isaacs, L. Cucurbit[7]Uril.Guest Pair with an Attomolar Dissociation Constant. Angew. Chemie Int. Ed. 2014, 53, 988-993.

(17) Moghaddam, S.; Yang, C.; Rekharsky, M.; Ko, Y. H.; Kim, K.; Inoue, Y.; Gilson, M. K. New Ultrahigh Affinity Host-Guest Complexes of Cucurbit[7]Uril with Bicyclo[2.2.2]Octane and Adamantane Guests: Thermodynamic Analysis and Evaluation of M2 Affinity Calculations. J. Am. Chem. Soc. 2011, 133, 3570-3581.

(18) Liu, S.; Ruspic, C.; Mukhopadhyay, P.; Chakrabarti, S.; Zavalij, P. Y.; Isaacs, L. The Cucurbit[ $n$ ] Uril Family: Prime Components for SelfSorting Systems. J. Am. Chem. Soc. 2005, 127, 15959-15967.

(19) Lee, D.-W.; Park, K. M.; Banerjee, M.; Ha, S. H.; Lee, T.; Suh, K.; Paul, S.; Jung, H.; Kim, J.; Selvapalam, N.; Ryu, S. H.; Kim, K. Supramolecular Fishing for Plasma Membrane Proteins Using an Ultrastable Synthetic Host-Guest Binding Pair. Nat. Chem. 2011, 3, 154-159.

(20) Hwang, I.; Baek, K.; Jung, M.; Kim, Y.; Kyeng, M. P.; Lee, D. W.; Selvapalam, N.; Kim, K. Noncovalent Immobilization of Proteins on a Solid Surface by Cucurbit[7]Uril-Ferrocenemethylammonium Pair, a Potential Replacement of Biotin-Avidin Pair. J. Am. Chem. Soc. 2007, 129, 4170-4171.

(21) Kim, K. L.; Sung, G.; Sim, J.; Murray, J.; Li, M.; Lee, A.; Shrinidhi, A.; Park, K. M.; Kim, K. Supramolecular Latching System Based on Ultrastable Synthetic Binding Pairs as Versatile Tools for Protein Imaging. Nat. Commun. 2018, 9, 1712.

(22) Li, W.; Bockus, A. T.; Vinciguerra, B.; Isaacs, L.; Urbach, A. R. Predictive Recognition of Native Proteins by Cucurbit[7]Uril in a Complex Mixture. Chem. Commun. 2016, 52, 8537-8540.

(23) An, J.; Kim, S.; Shrinidhi, A.; Kim, J.; Banna, H.; Sung, G.; Park, K. M.; Kim, K. Purification of Protein Therapeutics via High-Affinity Supramolecular Host-Guest Interactions. Nat. Biomed. Eng. 2020, 19.

(24) Mandadapu, V.; Day, A. I.; Ghanem, A. Cucurbituril: Chiral Applications. Chirality 2014, 26, 712-723.

(25) Chen, H.; Chen, Y.; Wu, H.; Xu, J.-F.; Sun, Z.; Zhang, X. Supramolecular Polymeric Chemotherapy Based on Cucurbit[7]Uril-PEG Copolymer. Biomaterials 2018, 178, 697-705.

(26) Young, J. F.; Nguyen, H. D.; Yang, L.; Huskens, J.; Jonkheijm, P.; Brunsveld, L. Strong and Reversible Monovalent Supramolecular 
Protein Immobilization. ChemBioChem 2010, 11, 180-183.

(27) Neirynck, P.; Brinkmann, J.; An, Q.; van der Schaft, D. W. J.; Milroy, L.-G.; Jonkheijm, P.; Brunsveld, L. Supramolecular Control of Cell Adhesion via Ferrocene-Cucurbit[7]Uril Host-Guest Binding on Gold Surfaces. Chem. Commun. 2013, 49, 3679-3681.

(28) Lee, D.-W.; Park, K. M.; Gong, B.; Shetty, D.; Khedkar, J. K.; Baek, K.; Kim, J.; Ryu, S. H.; Kim, K. A Simple Modular Aptasensor Platform Utilizing Cucurbit[7]Uril and a Ferrocene Derivative as an Ultrastable Supramolecular Linker. Chem. Commun. 2015, 51, 3098-3101.

(29) Jiao, D.; Zhao, N.; Scherman, O. A. A “Green” Method for Isolation of Cucurbit[7]Uril via a Solid State Metathesis Reaction. Chem. Commun. 2010, 46, 2007.

(30) Márquez, C.; Hudgins, R. R.; Nau, W. M. Mechanism of Host-Guest Complexation by Cucurbituril. J. Am. Chem. SOC 2004, 126, 58065816.

(31) Miskolczy, Z.; Megyesi, M.; Biczók, L.; Prabodh, A.; Biedermann, F. Kinetics and Mechanism of Cation-Induced Guest Release from Cucurbit[7]Uril. Chem. - A Eur. J. 2020, chem.201905633.

(32) Mock, W. L.; Shih, N. Y. Structure and Selectivity in Host-Guest Complexes of Cucurbituril. J. Org. Chem. 1986, 51, 4440-4446.

(33) von Ragué Schleyer, P.; Najafian, K. Stability and Three-Dimensional Aromaticity of Closo-Monocarbaborane Anions, CBn-1Hn- and ClosoDicarboranes, C2Bn-2Hn. Inorg. Chem. 1998, 37, 3454-3470.

(34) Chen, Z.; King, R. B. Spherical Aromaticity: Recent Work on Fullerenes, Polyhedral Boranes, and Related Structures. Chem. Rev. 2005, 105, 3613-3642.

(35) King, R. B. Three-Dimensional Aromaticity in Polyhedral Boranes and Related Molecules. Chem. Rev. 2001, 101, 1119-1152.

(36) Scholz, M.; Hey-Hawkins, E. Carbaboranes as Pharmacophores: Properties, Synthesis, and Application Strategies. Chem. Rev. 2011, 111, 7035-7062.

(37) Plesek, J. Potential Applications of the Boron Cluster Compounds. Chem. Rev. 1992, 92, 269-278.

(38) Blanch, R. J.; Sleeman, A. J.; White, T. J.; Arnold, A. P.; Day, A. I. Cucurbit[7]Uril and o-Carborane Self-Assemble to Form a Molecular Ball Bearing. Nano Lett. 2001, 2, 147-149.

(39) Wiesboeck, R. A.; Hawthorne, M. F. Dicarbaundecaborane(13) and Derivatives. J. Am. Chem. Soc. 1964, 86, 1642-1643.

(40) Hawthorne, M. F.; Young, D. C.; Garrett, P. M.; Owen, D. A.; Schwerin, S. G.; Tebbe, F. N.; Wegner, P. A. Preparation and Characterization of the (3)-1,2- and (3)-1,7-Dicarbadodecahydroundecaborate(-1) lons. J. Am. Chem. Soc. 1968, 90, 862-868.

(41) Plešek, J.; Heřmánek, S.; Štíbr, B.; Waksman, L.; Sneddon, L. G. Potassium Dodecahydro-7, 8-Dicarba- Nido -Undecaborate(1-), k[7, 8-c 2 b 9 h 12 ], Intermediates, Stock Solution, and Anhydrous Salt. Inorg. Synth. 2007, 22, 231-234.

(42) Fox, M. A.; Goeta, A. E.; Hughes, A. K.; Johnson, A. L. Crystal and Molecular Structures of the Nido-Carborane Anions, 7,9- and 2,9C2B9H12-. J. Chem. Soc. Dalt. Trans. 2002, 11, 2132-2141.

(43) Spokoyny, A. M.; Machan, C. W.; Clingerman, D. J.; Rosen, M. S.; Wiester, M. J.; Kennedy, R. D.; Stern, C. L.; Sarjeant, A. A.; Mirkin, C. A. A Coordination Chemistry Dichotomy for Icosahedral CarboraneBased Ligands. Nat. Chem. 2011, 3, 590-596.

(44) Herzog, A.; Maderna, A.; Harakas, G. N.; Knobler, C. B.; Hawthorne, M. F. A Camouflagednido-Carborane Anion: Facile Synthesis of OctaB-Methyl-1,2-Dicarba-Closo-Dodecaborane(12) and Its Deboration Reaction. Chem. - A Eur. J. 1999, 5, 1212-1217

(45) Dziedzic, R. M.; Axtell, J. C.; Rheingold, A. L.; Spokoyny, A. M. OffCycle Processes in Pd-Catalyzed Cross-Coupling of Carboranes. Org. Process Res. Dev. 2019, 23, 1638-1645.

(46) Zakharkin, L. L.; Ol'shevskaya, V. A.; Vorontsov, E. V.; Petrovsky, P. V. Synthesis of Mono-, Di-, Tri-, and Tetraethyl-o-Carboranes by Electrophilic Alkylation Ofo-Carborane with Ethyl Bromide in the Presence of $\mathrm{AICl} 3$ and Their Transformations. Russ. Chem. Bull. 1996, 45, 2614-2622.

(47) Andrews, J. S.; J, Z.; Jones, M. J. 9-lodo-o-Carborane. Inorg. Chem. 1985, 24, 3715-3716.
(48) Sieckhaus, J. F.; Semenuk, N. S.; Knowles, T. A.; Schroeder, H. Icosahedral Carboranes. XIII Halogenation of p-Carborane. Inorg. Chem. 1969, 8, 2452-2457.

(49) Dziedzic, R. M.; Saleh, L. M. A.; Axtell, J. C.; Martin, J. L.; Stevens, S. L.; Royappa, A. T.; Rheingold, A. L.; Spokoyny, A. M. B-N, B-O, and $\mathrm{B}-\mathrm{CN}$ Bond Formation via Palladium-Catalyzed Cross-Coupling of BBromo-Carboranes. J. Am. Chem. Soc. 2016, 138, 9081-9084.

(50) Sevryugina, Y.; Julius, R. L.; Hawthorne, M. F. Novel Approach to Aminocarboranes by Mild Amidation of Selected lodo-Carboranes. Inorg. Chem. 2010, 49, 10627-10634.

(51) Grushin, V. V.; Tolstaya, T. P.; Lisichkina, I. N. 9-o-Carboranyl Azide. Bull. Acad. Sci. USSR, Div. Chem. Sci. (Engl. Transl.) 1982, 31, 2329.

(52) Dziedzic, R. M.; Axtell, J. C.; Rheingold, A. L.; Spokoyny, A. M. OffCycle Processes in Pd-Catalyzed Cross-Coupling of Carboranes. Org. Process Res. Dev. 2019, 23, 1638-1645.

(53) Bockus, A. T.; Smith, L. C.; Grice, A. G.; Ali, O. A.; Young, C. C.; Mobley, W.; Leek, A.; Roberts, J. L.; Vinciguerra, B.; Isaacs, L.; Urbach, A. R. Cucurbit[7]Uril-Tetramethylrhodamine Conjugate for Direct Sensing and Cellular Imaging. J. Am. Chem. Soc. 2016, 138, 16549-16552.

(54) Zhou, X.; Su, X.; Pathak, P.; Vik, R.; Vinciguerra, B.; Isaacs, L.; Jayawickramarajah, J. Host-Guest Tethered DNA Transducer: ATP Fueled Release of a Protein Inhibitor from Cucurbit[7]Uril. J. Am. Chem. Soc. 2017, 139, 13916-13921.

(55) Vinciguerra, B.; Cao, L.; Cannon, J. R.; Zavalij, P. Y.; Fenselau, C.; Isaacs, L. Synthesis and Self-Assembly Processes of Monofunctionalized Cucurbit[7]Uril. J. Am. Chem. Soc. 2012, 134, 13133-13140.

(56) Mu, X.; Axtell, J. C.; Bernier, N. A.; Kirlikovali, K. O.; Jung, D.; Umanzor, A.; Qian, K.; Chen, X.; Bay, K. L.; Kirollos, M.; Rheingold, A. L.; Houk, K. N.; Spokoyny, A. M. Sterically Unprotected Nucleophilic Boron Cluster Reagents. Chem 2019, 5, 2461-2469.

(57) Keener, M.; Hunt, C.; Carroll, T. G.; Kampel, V.; Dobrovetsky, R.; Hayton, T. W.; Ménard, G. Redox-Switchable Carboranes for Uranium Capture and Release. Nature 2020, 577, 652-655.

(58) Fuentes, I.; Pujols, J.; Viñas, C.; Ventura, S.; Teixidor, F. Dual Binding Mode of Metallacarborane Produces a Robust Shield on Proteins. Chem. - A Eur. J. 2019, 25, 12820-12829.

(59) Fisher, S. P.; McArthur, S. G.; Tej, V.; Lee, S. E.; Chan, A. L.; Banda, I.; Gregory, A.; Berkley, K.; Tsay, C.; Rheingold, A. L.; Guisado-Barrios, G.; Lavallo, V. Strongly Coordinating Ligands To Form Weakly Coordinating Yet Functional Organometallic Anions. J. Am. Chem. Soc. 2020, 142, 251-256.

(60) Tao, G.; Duan, Z.; Mathey, F. Zwitterionic Nido -Carborane-Fused Phospholes. Org. Lett. 2019, 21, 2273-2276.

(61) Zhang, Y.; Yang, L.; Wang, L.; Duttwyler, S.; Xing, H. A Microporous Metal-Organic Framework Supramolecularly Assembled from a Cu " Dodecaborate Cluster Complex for Selective Gas Separation. Angew. Chemie Int. Ed. 2019, 58, 8145-8150.

(62) Yan, H.; Yang, F.; Pan, D.; Lin, Y.; Hohman, J. N.; Solis-Ibarra, D.; Li, F. H.; Dahl, J. E. P.; Carlson, R. M. K.; Tkachenko, B. A.; Fokin, A. A.; Schreiner, P. R.; Galli, G.; Mao, W. L.; Shen, Z.-X.; Melosh, N. A. Sterically Controlled Mechanochemistry under Hydrostatic Pressure. Nature 2018, 554, 505-510.

(63) Nghia, N. Van; Oh, J.; Sujith, S.; Jung, J.; Lee, M. H. Tuning the Photophysical Properties of Carboranyl Luminophores by Closo - to Nido -Carborane Conversion and Application to OFF-ON Fluoride Sensing. Dalt. Trans. 2018, 47, 17441-17449.

(64) Wang, H.; Zhang, J.; Lee, H. K.; Xie, Z. Borylene Insertion into Cage B$\mathrm{H}$ Bond: A Route to Electron-Precise B-B Single Bond. J. Am. Chem. Soc. 2018, 140, 3888-3891.

(65) Unfortunately, in TFA or $\mathrm{H}_{2} \mathrm{O}$ no significant chemical shift changes were observed by IR, ${ }^{11} \mathrm{~B}-\mathrm{NMR}$ or ${ }^{1} \mathrm{H}-\mathrm{NMR}$ spectroscopy precluding a $K_{a}$ determination of unfunctionalized carboranes (including nido-carborane) with $\mathrm{CB}[7]$ 